\title{
Correlation of level of TNF - $\square$ with severity of Diabetic Polyneuropathy in Type-2 Diabetes Mellitus
}

\author{
Debarati Chanda ${ }^{1}$, Shouvanik Adhya ${ }^{2}$

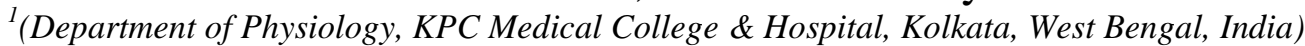 \\ ${ }^{2}$ (Department of Forensic Medicine, College of Medicine \& JNM Hospital, WBUHS, Kalyani, \\ West Bengal, India)
}

\begin{abstract}
Diabetic poly neuropathy (DPN) is the most common chronic complication of type 2 diabetes. Aim of this observational cross sectional study is to establish correlation between level of TNF $\alpha$ and severity of DPN if any. The forty seven subjects were divided into three groups. Group1:15 healthy normal controls; Group2:12 T2DM patients without neuropathy controls; Group3:20 T2DM patients with painful neuropathy case. To measure TNF- $\alpha 5 \mathrm{ml}$ blood was drawn and centrifuged and then TNF- $\alpha$ measurement was done with Ray Bio Human TNF- $\alpha$ ELISA kit. Plasma TNF- $\alpha$ shows high correlation with progress of neuropathy; In early phases of diabetes (group2) TNF- $\alpha$ shows a tendency to rise, which increases further with development of overt painful neuropathy (group3).
\end{abstract}

Keywords: Diabetic polyneuropathy, $T N F-\alpha$, type-2 diabetes mellitus.

\section{Introduction}

Diabetes mellitus (DM) is a metabolic disorder of multiple aetiologies. Type 2 diabetes is the most common form of diabetes ${ }^{[1]}$. Most common microvascular chronic complication of type 2 diabetes is diabetic poly neuropathy (DPN) ${ }^{[2]}$. Pathogenesis of DPN is multifactorial which includes elevation of several cytokines like Tumour Necrosis Factor $\alpha$ (TNF $\alpha$ ), Interleukin 6 (IL6) etc ${ }^{[3]}$. TNF- $\alpha$ exhibit pleiotrophic effects on glia cells and neurons important for the homeostasis of the peripheral, central, and autonomic nervous systems ${ }^{[4,5]}$.

Role of TNF $\alpha$ in development of DPN has been studied in several ways in different corners of the world. In a Japanese study Jo Satoh et $\mathrm{al}^{[6]}$ showed that augmented expression and production of TNF- $\alpha$ are strongly implicated in the pathogenesis of diabetic polyneuropathy and suppressants of TNF- $\alpha$ are beneficial for alleviating signs and symptoms of this intractable disorder. A study conducted by Clemente-Gonzalez et al ${ }^{[7]}$ in Spain, it was observed that the activity of the TNF-alpha system is increased in subjects with diabetic neuropathy, regardless of their glycaemic control. In a multicentric experiment with rodent Yamakawa Isamu et al ${ }^{[8]}$ showed that when compared with non-diabetic mice, TNF- $\alpha$ positive diabetic mice displayed significant impairments of nerve functions. In contrast diabetic TNF- $\alpha$ negative mice showed no evidence of abnormal nerve function tests compared with non-diabetic mice. Galloway $\mathrm{C}^{\left[{ }^{[9]}\right.}$ in his animal study found that there is increase in TNF- $\alpha$ at the onset of pain in DPN of T2DM. Doupis J et al ${ }^{[10]}$ showed that increased level of plasma TNF- $\alpha$ is associated with DPN. One interesting conclusion they found is that painful neuropathy is associated with further increased level of inflammatory markers.

Aim of the present study is to establish correlation between level of TNF $\alpha$ and severity of DPN if any.

\section{Materials And Methods}

This study is an observational cross sectional study. It was conducted upon human subjects. They gave their consents for being included in the study.

The study was carried out in the Department of Physiology, in collaboration with the Department of Endocrinology in I.P.G.M.E\&R, S.S.K.M Hospital, Kolkata during the period of 2012-2013.

Sample size was 47. The subjects were divided into three groups.

Group1: 15 healthy normal controls.

Group2: 12 T2DM patients without neuropathy controls.

Group3: 20 T2DM patients with painful neuropathy case.

Exclusion criterion: Patients of T2DM with only DPN are included and patient having neuropathy of other causes or retinopathy and nephropathy are excluded.

Ethical consideration: Study was conducted after getting clearance from Institutional Ethical Committee. Patients were provided with protocol and their informed consents were taken. Data collection method was explained in detail to the patients.

Confidentiality: Identity of the patients cannot be revealed from the collected data. 
Procedure for data collection: To assess severity of neuropathy detailed history and total neuropathy score (TNS) for each patient was determined.TNS ${ }^{[11]}$ includes sensory motor symptoms, pin sensitivity, vibration sense, muscle power, deep tendon reflexes, vibration perception threshold and lastly sensory and motor nerve conduction test.

To measure TNF- $\alpha 5 \mathrm{ml}$ blood was drawn and centrifuged to separate plasma and then TNF- $\alpha$ measurement was done with Ray Bio Human TNF- $\alpha$ ELISA kit ${ }^{[12]}$.

Source of finance: Project grant from Endocrine Dept of IPGME\&R.

Plan of Analysis: The results were expressed as mean \pm SD. p $<0.05$ were considered significant. One way ANOVA and Student's paired t-test and correlation analysis have been applied. Statistical analysis was done by using the software GRAPHPAD PRISM Version 5.00 March 7, 2007.

\section{Results}

In this study 47 subjects were selected and grouped in three categories. Severity of neuropathy was assessed and its correlation with plasma TNF- $\alpha$ level was determined. Difference of plasma TNF- $\alpha$ level between normal control (goupr1) and diabetic control (group2) is highly significant $(\mathrm{p}<0.05)$ as shown in Table 1.Table 2 shows difference of plasma TNF- $\alpha$ level between normal control (group1) and painful neuropathy group (group3) is highly significant $(\mathrm{p}<0.05)$. Also it is observed in Table 3 that the difference of plasma TNF$\alpha$ level between diabetic control (group2) and painful neuropathy group(group3) is highly significant $(\mathrm{p}<0.05)$.

\section{Discussion}

The present study was conducted to find if any relation exists between plasma TNF- $\alpha$ concentration and diabetic neuropathy in patients with type 2 diabetes (T2DM).

In present study it is observed that Difference of plasma TNF- $\alpha$ level between normal control and diabetic control is highly significant and also concentration of TNF- $\alpha$ in diabetic neuropathy patient is significantly increased than diabetic control group.

Jo Satoh et al ${ }^{[6]}$ showed that enhanced expression and production of TNF- $\alpha$ is strongly implicated in the pathogenesis of diabetic polyneuropathy. Our present study also agrees with the finding. In the work of Clemente-Gonzalez ${ }^{[7]}$ et al it is observed that the activity of the TNF-alpha system is increased in subjects with diabetic neuropathy, regardless of their glycaemic control. This finding is in accordance with our observation. In a recent multicentric experiment with rodent Yamakawa Isamu ${ }^{[8]}$ et al found that when compared with nondiabetic mice, $\mathrm{TNF}=\alpha$ positive diabetic mice displayed significant impairments of nerve functions. But diabetic TNF- $\alpha$ negative mice developed no signs of abnormal nerve function tests when compared with non-diabetic mice. This is also in accordance with our observation as we have found increased TNF- $\alpha$ concentration in DPN study. Galloway $\mathrm{C}^{[9]}$ in his animal study found that there is increase in TNF- $\alpha$ at the onset of pain in DPN of T2DM. This is similar to our observation. Similar results were also observed by Doupis J et al ${ }^{[\mathbf{1 0}]}$.

\section{TABLES \& FIGURES}

Table 1: Comparative study of plasma TNF- $\alpha$ level between normal control (group1) \& diabetic control (group2)

\begin{tabular}{|l|l|l|l|}
\hline parameters & $\begin{array}{l}\text { Group1 } \\
\text { Mean } \pm \text { SD }\end{array}$ & $\begin{array}{l}\text { Group2 } \\
\text { Mean } \pm \text { SD }\end{array}$ & Stat sig (P value) \\
\hline TNF- $\alpha(\mathrm{pg} / \mathrm{ml})$ & $221.7 \pm 46.91$ & $743.6 \pm 87.27$ & $<0.0001$ \\
\hline
\end{tabular}

Difference of plasma TNF- $\alpha$ level between normal control and diabetic control is highly significant.

Table 2: Comparative study of plasma TNF- $\alpha$ level between normal control (group1) and painful neuropathy group (group3)

\begin{tabular}{|l|l|l|l|}
\hline Parameters & $\begin{array}{l}\text { Group1 } \\
\text { Mean } \pm \text { SD }\end{array}$ & $\begin{array}{l}\text { Group 3 } \\
\text { Mean } \pm \text { SD }\end{array}$ & Stat sig (P value) \\
\hline TNF- $\alpha(\mathrm{pg} / \mathrm{ml})$ & $221.7 \pm 46.91$ & $1343 \pm 283.8$ & $<0.0001$ \\
\hline
\end{tabular}

Difference of plasma TNF- $\alpha$ level between normal control and painful neuropathy group is highly significant.

Table 3: Comparative study of plasma TNF- $\alpha$ level between diabetic control (group2) and painful neuropathy group (group3)

\begin{tabular}{|l|l|l|l|}
\hline Parameters & $\begin{array}{l}\text { Group2 } \\
\text { Mean } \pm \text { SD }\end{array}$ & $\begin{array}{l}\text { Group 3 } \\
\text { Mean } \pm \text { SD }\end{array}$ & Stat sig (P value) \\
\hline TNF- $\alpha(\mathrm{pg} / \mathrm{ml})$ & $743.6 \pm 87.27$ & $1343 \pm 283.8$ & $<0.0001$ \\
\hline
\end{tabular}

Difference of plasma TNF- $\alpha$ level between diabetic control and painful neuropathy group is highly significant. 
Figure 1: Distribution of TNF- $\alpha$ level (pg/ml) between normal control (group1), diabetic control (group2) and painful neuropathy (group3)

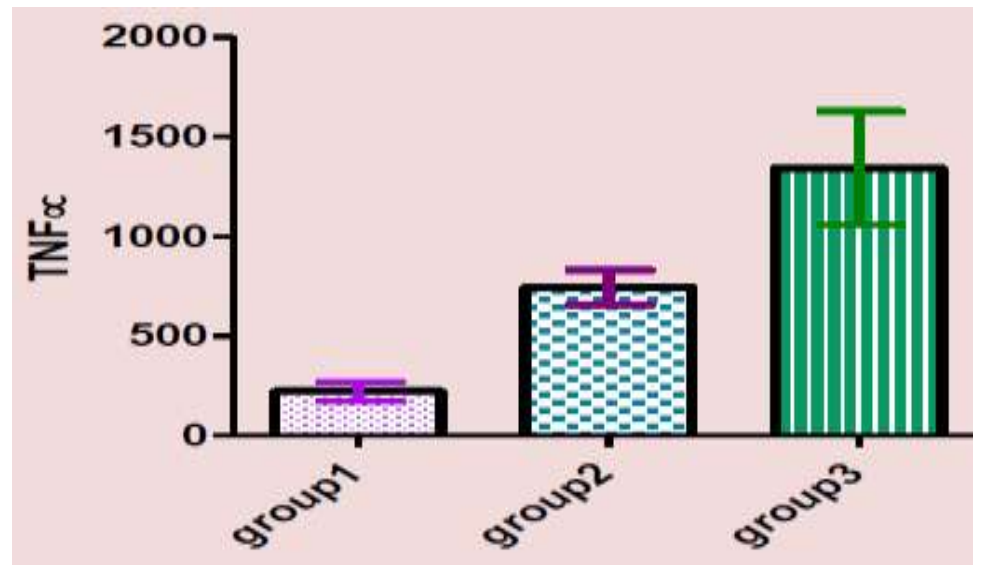

V. Conclusion

From our present study we can arrive at the following conclusion: Pro-inflammatory marker (TNF- $\alpha$ ) shows high correlation with progress of neuropathy In early phases of diabetes (group2) TNF- $\alpha$ shows a tendency to rise, which increases further with development of overt painful neuropathy (group3).This observation leads us to the inference that TNF- $\alpha$ plays a key role in development and progress of neuropathy and increase in concentration of TNF- $\alpha$ with severity of neuropathy suggests that initiates and promotes development of nerve dysfunction in DPN.

\section{References}

[1]. Kaveeshwar S A,Cornwall J.The current state of Diabetes Mellitus in India. Australas Med J. 2014; 7(1): 45-48.

[2]. Cameron N E, Cotter M A. Pro inflammatory mechanisms in diabetic neuropathy: focus on NFkB pathway. Current drug targets. 2008; 9:60-67.

[3]. Armati P J, Pollard J D. Immunology of Schwann cell.Bailliere's clin.neurol.1996;5:47-64

[4]. Chalazonitis A, Rothman T P, Chen J, Gershon M D. Age-dependent differences in the effects of GDNF and NT-3 on the

[5]. development of Neurons and Glia from Neural Crest Derived Precursors Immunoselected from the Fetal Rat Gut : expression of GFRalpha1 in vitro and in vivo. Devel.Biol.1998;204:385-406.

[6]. Saoh J, Yagihashi S, Toyota T. The possible role of TNF alpha in diabetic polyneuropathy. Experimental Diab.Res.2003;4:65-71

[7]. Clemente-Gonzalez JM, Mauricio D, Richart C et al. Diabetic neuropathy is associated with activation of TNF alpha system in subjects with T1DM.Clin Endcrinol(oxf).2005;63(5):525-529.

[8]. Yamakawa I, Kojima H, Terashima T, Katagi M, Oi J, Urabe H et al. Inactivation of TNF-a ameliorates diabetic neuropathy in mice. Am J Physiol Endocrinol Metab 2011; 301:E844-E852.

[9]. Galloway C, Chattopadhyay M. Increase in inflammatory mediators in DRG implicate in the pathogenesis of painful neuropathy in Type 2 Diabetes.Cytokine2013jul; 63(1):1-5.

[10]. Doupis J, Lyons TE, Wu S, Gnardellis C, Dinh T, Veves A. Microvascular reactivity \& inflammatory cytokines in painful and painless neuropathy. J Clin Endocrinol Metab.2009 jun;94(6):2157-2163.

[11]. Cavaletti G,Bogliun G, Marzorati L, Zincone A, Piatti M, Colombo N et al. Grading of chemotherapy-induced peripheral neurotoxicity using the Total Neuropathy Scale. Neurology 2003Nov 11; 61(9): 1297-1300.

[12]. Human TNF $\alpha$ ELISA kit. www.raybiotech.com. 